\title{
ANTECEDENTES HISTÓRICO - JURÍDICOS DEL COMERCIO INTERNACIONAL CONTEMPORÁNEO
}

\author{
Salvador Francisco Ruiz Medrano ${ }^{1}$
}

\section{Resumen}

El sistema multilateral de comercio, es un sistema en el que se ha formado un ideal común de un comercio mundial equitativo y abierto. Un sistema que ha contribuido directamente a la supresión de obstáculos al comercio entre los Estados y un sistema cuya estructura está basada en normas de carácter jurídico y el principio de no discriminación. El actual sistema del comercio multilateral ha sido moldeado a lo largo de los últimos 50 años del siglo XX, periodo en el que se crean y se perfilan la existencia de las instituciones económicas multilaterales. Este sistema descansa sobre una estructura internacional de reglas y obligaciones que regulan el comercio entre los Estados, el análisis evolutivo que se ha de hacer en torno a este se hace por tanto indispensable para comprender el futuro del comercio internacional.

Palabras-clave: comercio internacional, antecedentes históricos, derecho del comercio internacional, derecho internacional privado.

\section{UNA PERSPECTIVA GENERAL DE LOS ANTECEDENTES DEL GATT Y LA OMC.}

Desde antes de concluir la Segunda Guerra Mundial, se conjeturó lo que serían las nuevas relaciones económicas internacionales de forma que al concluir la Segunda Guerra Mundial los países, y sobre todo Estados Unidos, deseaban impulsar rápidamente las relaciones económicas y la liberalización del comercio y con ello comenzar a destrabar las imponentes medidas proteccionistas que se conservaban en vigor desde comienzos de 1930. Los Estados Unidos, fueron los incitadores del GATT, al igual que el FMI y el BMRF. La razón de dicha proposición fue que, en 1945, el congreso de los Estados Unidos había otorgado una autorización para reducir los aranceles de manera recíproca en un 50\% en un periodo de tres años, el cual expiraba a finales de 1948, para Estados Unidos era primordial garantizar sus intereses, los cuales se concretarían, con la negociación de un acuerdo con tales características y antes que cualquier otra cosa debía de asegurarse de cumplir su objetivo, de otra forma su comercio se vería afectado (Millet, 2001, pág. 29).

Así, se celebraron las conferencias de Bretton Woods, donde se abordaron temas que significaban un

\footnotetext{
${ }^{1}$ Doctor en Derecho Internacional Privado por la Universidad de Valencia, España, con especialidad en Propiedad Intelectual. Profesor de tiempo completo del Departamento de Gestión y Dirección de Empresas de la División de Ciencias Económico Administrativas de la Universidad de Guanajuato. E-mail: salvador.rm@ugto.mx
} 
problema para el nuevo orden económico mundial, así, se pensó y se dio solución a los inconvenientes que ya se venían dando en los años anteriores, por un lado, el tema de los tipos de cambio paro lo que se creó el Fondo Monetario Internacional (FMI), al cual se le encomienda vigilar, el correcto funcionamiento del sistema monetario internacional, desempeñar una actividad de cooperación mediante asistencia financiera y asesorar a sus miembros. Otra de las cuestiones fue el tema de la reconstrucción para lo que se crea una institución bancaria internacional que proporcionará préstamos con tal fin surgiendo así el Banco Mundial (BM). Estas instituciones financieras de Bretton Woods permitieron dar un nuevo enfoque a la economía mundial accediendo a adecuar los flujos financieros internacionales, pero, además, también había que considerar una institución que pugnará por el comercio internacional, aunque los dos órganos anteriores, de alguna manera, tenían la función de estimularlo (Negro, 2004, pág. 344). De esta forma, en las mismas conferencias de Bretton Woods se planteó la situación de regular el comercio internacional para mejorar las relaciones económicas internacionales (Millet, 2001, pág. 27 y 28).

La Organización de las Naciones Unidas (ONU), por su parte tenía claro que era necesario regular y velar por los asuntos internacionales de carácter económico, para lo cual, y al constituirse las Naciones Unidas, también se establecieron varios órganos entre ellos, un Órgano Económico y Social de las Naciones Unidas (United Nations Economic and Social Council, ECOSOC) ${ }^{2}$. El mandato de lo anterior, encuentra su fundamento en su Carta Constitutiva ${ }^{3}$, donde estableció como una de sus finalidades la de "...promover el progreso social y a elevar el nivel de vida...", y para dar cumplimiento a esto, se comprometieron a cooperar en el ámbito de las relaciones comerciales y a dar solución a problemas internacionales de carácter económico, dejando en el documento la puerta abierta a la posibilidad de constituir una organización internacional para fomentar "...el progreso económico y social de los pueblos", en consideración a que uno de los designios de la Organización es el de establecer una cooperación internacional, que sirva como plano para dar solución a dificultades internacionales de carácter económico (Varela Parache, 1969, pág. 157).

Ante estas ideas, los Estados Unidos, con sus ideas comerciales internacionales liberales pugnaban por completar el orden económico internacional, con la instauración de un Organismo Internacional de Comercio (OIC), todo ello con intereses propios, siendo uno de ellos el de dar salida a los cuantiosos stocks de productos que la industria norteamericana había acumulado en los años de la guerra, así que tenía que garantizar sus mercados para colocar sus productos y así continuar con su nivel de crecimiento y su nivel de empleo (De la Peña, 1980, pág. 35) (Álvarez Soberanis, 1979, pág. 111) de esta forma y sin titubeos, la intención de los Estados Unidos fue el de buscar el libre acceso a los mercados internacionales para vender sus mercancías como para

\footnotetext{
${ }^{2}$ Es el órgano especializado de la ONU, al cual le compete hacer las recomendaciones y convocar conferencias Internacionales sobre asuntos de carácter económico.

${ }^{3}$ Carta de San Francisco, la cual entro en vigor el 24 de octubre de 1945.
} 
proveerse de materias primas (Álvarez Soberanis, 1979, pág. 111)

El secretario de Estado norteamericano William L. Clayton plasmo sus ideas en un documento llamado Proposals for expansion of World Trade and Employment (también conocido como Plan Clayton), mismo que proponía establecer un comercio multilateral, sobre bases estables, amplias y no preferenciales. Dicho documento fue acogido por el gobierno Estadounidense y dado a conocer por el presidente Roosevelt en 1945 ante el Congreso de su mismo país (Álvarez Soberanis, 1979, pág. 111), ante el que manifestó la necesidad de complementar y alcanzar los fines del sistema de Bretton Woods con un nuevo sistema internacional de comercio, al margen de una organización internacional comercial, que contribuyera en reducir obstáculos a los intercambios internacionales de mercancías, lo cual daría margen una mayor eficacia económica, a un mayor bienestar internacional, así como asegurar las condiciones de una paz mundial duradera. La idea fue planteada a Gran Bretaña y ambos países acordaron darla a conocer en ese mismo año, a la recién creada ONU.

Finalmente, el plan fue propuesto al Consejo Económico y Social de la organización de las Naciones Unidas quien mediante una resolución adoptada el 18 de febrero de 1946 donde se convocó a una Conferencia Internacional sobre Comercio y Empleo, con el propósito de favorecer las relaciones económicas y el comercio Internacional, así como para considerar la creación de la Organización Internacional de Comercio (Díaz Mier, 1996, pág. 21) (Montaña Mora, 1997, pág. 11) (Tamames \& Huerta, 2003, pág. 155).

El Consejo con el designio de preparar la conferencia y trabajar sobre la redacción y fundamentos de la Carta que constituiría la OIC, toma la iniciativa de establecer un Comité Preparatorio, al que se le asignaron dichas tareas, mismas que se desarrollaron en dos reuniones preparatorias las cuales fueron celebradas en Londres en 1946 y en Ginebra en 1947, en las que intervinieron 17 países (Millet, 2001, pág. 28). Después de estas reuniones previas, finalmente, se abren las negociaciones para crear la OIC, celebrándose la Conferencia de las Naciones Unidas sobre Comercio y Empleo, en La Habana, Cuba, la cual dio inicio el 21 de noviembre de 1947 y concluyo con la Firma del Acta Final de 53 países participantes4 el 24 de marzo de 1948. En la Conferencia se redactó y se adoptó “La Carta de La Habana” en la que se instituía la Organización Internacional de Comercio. Sin embargo, es de señalarse que en las negociaciones de la Carta de La Habana se expusieron intereses opuestos, como era de esperarse, por un lado los de los Estados Unidos y gran Bretaña, quienes apostaban por un sistema liberal de comercio y por el otro lado los intereses de los países que en su momento eran considerados como subdesarrollados, quienes pugnaban por un comercio internacional que estuviera relacionado con desarrollo

\footnotetext{
${ }^{4}$ Afganistán, Australia, República de Austria, el Reino de Bélgica, Bolivia, China, Colombia, Brasil, la Unión Birmana, Canadá, Ceilán, Chile, Irán, Iraq, Costa Rica, Cuba, Checoslovaquia, Dinamarca, la República Dominicana, Ecuador, Egipto, El Salvador, Francia, Grecia, Guatemala, Haití, India, República de Indonesia, República Filipina, Portugal, Rodesia del Sur, Irlanda, República de Italia, Líbano, Liberia, el Gran Ducado de Luxemburgo, México, Reino de los Países Bajos, Nueva Zelanda, Nicaragua, el Reino de Noruega, Pakistán, Panamá, Perú, Unión Sudafricana, el Reino Unido de la Gran Bretaña e Irlanda del Norte, Suecia, Suiza, Siria, Jordania, los Estados Unidos de América, Uruguay, y Venezuela.
} 
económico y el pleno empleo, a la vez que también buscaban establecer mecanismos jurídicos que protegieran las fluctuaciones de los productos básicos (De la Peña, 1980, pág. 35 y 36).

Los objetivos ${ }^{5}$ inmediatos de la Carta serían los de lograr el desarrollo económico y la reconstrucción, el acceso de todos los países, en condiciones de igualdad, a los mercados, a las fuentes de aprovechamiento y a los medios de producción; la reducción de los obstáculos al comercio y la consulta y cooperación en el seno de la Organización Internacional de Comercio. Como último objetivo, estaría el de alcanzar el pleno empleo a través del crecimiento del comercio internacional (Patiño Manfer, 1994, pág. 733). En si los propósitos de la Carta de La Habana eran los de cumplir los objetivos de la Carta de las Naciones Unidas enunciados en su Artículo 55.

La "Carta de La Habana, para una Organización Internacional de comercio" (que fue así como se le denominó) (Patiño Manfer, 1994, pág. 733), estaba integrada por 106 artículos los cuales se dividían en nueve capítulos; I. Propósitos y Objetivos; Capitulo II. Empleo y Actividad Económica; III. Desarrollo Económico y Reconstrucción; IV. Política Comercial; V. Prácticas Comerciales Restrictivas, VI. Convenios Intergubernamentales sobre Productos Básicos; Capitulo VII La Organización Internacional de Comercio; Capitulo VIII. Solución de Controversias y Capitulo IX. Disposiciones Generales, y 16 anexos.

\section{La Organización Internacional del Comercio}

La OIC, estaría destinada principalmente a servir como cuadro institucional para la regulación y desarrollo del comercio internacional, por lo que ésta, no sólo se le habría encomendado la regulación del comercio internacional, sino también todas aquellas relaciones internacionales estrechamente vinculadas al comercio, a lo que la Carta pasaría a ser el instrumento jurídico-económico de carácter mundial, y un "Código de comercio Internacional" (Varela Parache, 1969, pág. 157) por recoger las disposiciones que regularían las relaciones económicas y el comercio internacional.

Con aplicación de la Carta de La Habana, se pronosticaba una relación económica y comercial internacional, regulada por una institución (OIC) que aseguraría una armonía y cooperación para la expansión del comercio mundial, más, sin embargo, aun y con los puntos bien establecidos y claros la Carta de La Habana fue firmada por los 58 países suscriptores, pero no ratificada, por lo que nunca entro en vigor. Para que la Carta hubiese entrado en vigor convino ser ratificada, por un mínimo de 20 miembros $^{6}$, pero solo la ratificaron dos:

\footnotetext{
${ }^{5}$ En el Artículo I de la "Carta de La Habana" se establecen sus objetivos los cuales se resumen en: Asegurar, aumentar, equilibra y expandir las relaciones económicas y comerciales Internacionales; Fomentar; apoyar y ayudar a los países al desarrollo industrial:Impulsar el desarrollo económico sobre la base de la reciprocidad de las relaciones económicas y del comercio; Promover, la reducción de los aranceles aduaneros y demás barreras comerciales, y la eliminación del tratamiento discriminatorio en el comercio Internacional; y Establecer la Organización Internacional del Comercio. Consultado en: https://www.wto.org/spanish/docs_s/legal_s/havana_s.pdf, pág. 13 consultado el 25 de mayo de 2017.

${ }^{6}$ Artículo 103.2 párrafo 2 de la Carta de La Habana, 1948.
} 
Australia y Liberia (Varela Parache, 1969, pág. 158).

De haber entrado en vigor la Carta, la OIC, habría sido un organismo subsidiario y especializado de las Naciones Unidas ${ }^{7}$, y que hubiese establecido las disciplinas para el comercio mundial y al que se le hubiera encomendado, promover el empleo y el desarrollo de los intercambios comerciales, además de que hubiese cumplido con los propósitos y objetivos establecidos en "La Carta de La Habana”en su artículo I.

Algunas de las principales funciones encomendadas a la OIC eran:

1. Servir de órgano asesor sobre comercio Internacional, políticas y prácticas comerciales y desarrollo económico en general;

2. Funcionar como órgano consultivo, ya que sus miembros podían discutir en el plano de la organización todos los asuntos concernientes a la solución de los problemas de comercio Internacional, al empleo, al desarrollo económico, a la política comercial, a las prácticas comerciales y a la política en materia de productos básicos, así como a todos los asuntos relativos a las disposiciones de la Carta, y;

3. Estimular la consumación de convenios bilaterales o multilaterales sobre comercio Internacional destinadas a facilitar el arbitraje comercial ${ }^{8}$.

El motivo, de carácter técnico, por el que la Carta de La Habana nunca entró en vigor, fue por la negativa de la mayoría de los países signatarios, a ratificarla ya que los países signatarios habían acordado, que para que la Carta entrará en vigor sería necesario ser ratificada, mínimo por el 85\% de países signatarios que en conjunto participaran en esos momentos en el comercio mundial (Patiño Manfer, 1994, pág. 733).

Otras causas por las que no se ratificó la Carta fueron diversas, una de ellas, se atribuyen a las hostilidades después de la guerra: el mundo se encontraba dividido en dos bloques con diferentes tendencias e ideologías, mismas que confrontaron a las dos grandes potencias Estados Unidos y la Unión de Repúblicas Socialistas Soviéticas (la extinta URSS), lo que llevo a una polarización de opiniones y caminos que pudieran llevar al bienestar social a la humanidad, siendo esta carta vista como una imposición de corte capitalista por parte del bloque de países comunistas quienes al final se abstuvieron de ratificar.

Por otro lado, pudo haber sido que, en el momento de las negociaciones de la Carta de La Habana, los países desarrollados, como los subdesarrollados no estuvieran de acuerdo en el resultado de la Carta por no convenir a sus intereses, principalmente a los de los Estados Unidos y la Gran Bretaña quienes apostaban por el restablecimiento del comercio liberal en función de una supuesta de igualdad formal de todos los países comerciantes basándose en la aplicación de la cláusula de nación más favorecida; por el contrario, la postura que

\footnotetext{
${ }^{7}$ Actualmente la Asamblea General de la ONU señala que los órganos subsidiarios se dividen en las siguientes categorías: Comités, Comisiones, Juntas, Consejos y Grupos, y Grupos de trabajo y otros, de donde cabría destacar el Consejo Económico y Social quien actúa como foro central para el debate de cuestiones internacionales de índole económica y social.

${ }^{8}$ Vid., Artículo 72 de la Carta de La Habana, 1948.
} 
adoptaron los países subdesarrollados (entre ellos India, Uruguay, Brasil, Chile y Australia),fue la de regular el comercio internacional, observando sobre todo los precios de los productos básicos, el empleo y la actividad económica, el desarrollo económico y las prácticas de negociaciones restrictivas. Posturas que no convenían del todo a ninguna de las dos partes (Witker, Principios y estructura del GATT, 1979) (Patiño Manfer, 1994, pág. 734).

Sin embargo, la negativa del Senado de los Estados Unidos, fue quizás, la principal causa a ratificar la Carta de La Habana, alegando que esta no resultaba suficientemente liberal y que hacía demasiado énfasis en los méritos de planeación económica. Lo que accionó de alguna manera a que el resto de países se abstuvieran de firmar (Witker \& Hernández, Régimen Jurídico del comercio exterior en México, 2002, pág. 53). Tampoco hay que dejar de considerar que, en el proyecto de la Carta, se trató de comprender los aspectos más importantes de la actividad mercantil, pero para una atmósfera aun salpicada por los estragos de la guerra, era hasta cierto punto ambicioso y lo que hizo difícil su negociación. Aun así, la Carta de La Habana no fue del todo improductiva, ya que la misma ONU, adoptó el capítulo VI de la Carta, relativo a la regulación jurídica internacional en materia de convenios comerciales sobre productos básicos (Álvarez Soberanis, 1979, pág. 118).

\section{EL GATT COMO UN ANTECEDENTE DE LA ORGANIZACIÓN MUNDIAL DEL COMERCIO (OMC)}

\section{Orígenes del GATT}

El origen del GATT se remonta a las reuniones previas a la celebración de la Conferencia Internacional de las Naciones Unidas sobre Comercio y Empleo, para la creación de la OIC, naciendo, por tanto, en el seno de la ONU. Los miembros del Comité Preparatorio, por iniciativa de los Estados Unidos, aprovecharon las reuniones como foro, para versar sobre temas que consideraron prioritarios por perturbar al comercio internacional, destacando el alto grado de proteccionismo al comercio interno, y las restricciones a las importaciones. Tales problemas no podían esperar a que se creara la OIC (De la Peña, 1980, pág. 36).

Una vez acogida la idea por los países participantes en las reuniones, acordaron y formularon las reducciones arancelarias, decidiendo dar solución a una de sus principales trabas al comercio internacional, tratando de eliminar disposiciones proteccionistas y aranceles aduaneros. Así surgió, el Acuerdo general sobre Aranceles y Comercio (el GATT). El acuerdo tendría el carácter de acuerdo provisional hasta que se fundara la OIC, una vez ratificada la Carta que diera origen a OIC, el GATT, pasaría a ser la parte comercial de la Carta. 
Así, el Acuerdo, fue firmado por 23 países 9 , el 30 de octubre de 1947, y entro en vigor el 1 de enero de 1948 de manera provisional hasta el 31 de diciembre de 1994 (Witker \& Hernández, Régimen Jurídico del comercio exterior en México, 2002, pág. 52). Una vez que la Carta de La Habana no fue ratificada, y por consiguiente la OIC, no fue instituida, el GATT, se transformó en el único marco institucional regulador del comercio internacional y la única garantía para la liberalización del comercio mundial. De no haber sido por las negociaciones del comité preparatorio para trabajar y dar origen al GATT, el comercio, la economía y las relaciones internacionales se hubiera visto muy seguramente dañadas y con un lento desenvolvimiento.

Existen varias opiniones encontradas de sí el GATT fue un sistema provisional, un simple acuerdo comercial o si fue una organización formal de comercio, lo que sí es verdad, es que desde el momento en que la OIC no se constituyó, el GATT fue el convenio comercial más importante; el marco que reguló el comercio internacional hasta la constitución de la OMC y, que como acuerdo internacional estableció derechos y obligaciones para los países que los suscribieron.

El GATT centra la regulación del comercio internacional en los aranceles de aduanas, como únicos instrumentos de control de comercio entre países, sus objetivos, una vez que logra despejar los otros obstáculos al comercio exterior, es rebajar los niveles arancelarios a través de progresivas negociaciones que tienen como fundamento la reciprocidad y ventajas mutuas entre las partes (Witker, Principios y estructura del GATT, 1979, pág. 782).

\section{Los objetivos del GATT}

Los objetivos del GATT los encontramos en su preámbulo, donde su objetivo principal es el de reducir los aranceles y suprimir las barreras al comercio internacional entre sus miembros; fomentar entre los Estados las relaciones comerciales y económicas; lograr al mejoramiento de los niveles de vida y el pleno empleo a través de estas relaciones; así como lograr que los Estados colaboren para satisfacer sus necesidades beneficiándose con los recursos mundiales. Por tanto, su finalidad primordial del GATT fue la de liberalizar el comercio, y que finalmente tuvo éxito sobre todo por el interés máxime de los bienes que atañín a los principales productores mundiales.

\section{Naturaleza jurídica del antiguo GATT}

La naturaleza jurídica trató de manifestarse como un Acuerdo Internacional, como una Institución Internacional y como un Tribunal Internacional (Witker, Principios y estructura del GATT, 1979, pág. 783), aun

\footnotetext{
${ }^{9}$ Los Gobiernos del Commonwealth de Australia, Reino de Bélgica, Birmania, Estados Unidos del Brasil, Canadá, Ceilán, República de Cuba, República Checoslovaca, República de Chile, República de China, Estados Unidos de América, República
} 
y cuando en estos aspectos fracasó, puesto que al carecer de personalidad jurídica, patrimonio propio y del status que deben de ostentar las instituciones internacionales reconocidas por los Estados no se cumplían, por lo que el GATT quedo únicamente como un Tratado Internacional de carácter temporal, esto fue así, en virtud de que una organización debe contar al nacer de un tratados internacional constitutivo o fundacional, los cuales son, al igual que cualquier otro tratado internacional, normas de derecho internacional que obligan a los Estados signatarios entre sí y frente a tercero países y cumplen con lo que se observa en el artículo 6 de la Convención de Viena, sobre el Derecho de los Tratados entre Estados y Organizaciones Internacionales o entre Organizaciones Internacionales ${ }^{10}$ el cual a letra explica: "La capacidad de una organización internacional para celebrar tratados se rige por las reglas de esa organización", cuestión con la que no cumplió el GATT.

Desde un punto de vista técnico jurídico, desempeñó un papel importante para el derecho del comercio internacional, a la vez que también ha significado una de las principales fuentes de este derecho. Sin lugar a duda ha hecho una considerable contribución al campo del derecho aduanero: ha favorecido a una nomenclatura arancelaria uniforme, ha establecido un lenguaje comercial común, y, por supuesto ha creado un derecho jurisprudencial comercial internacional de alto valor científico (Witker, Principios y estructura del GATT, 1979, pág. 783) (Montaña Mora, 1997, pág. 3).

El GATT, por su naturaleza jurídica contemplo casi por 46 años una doble función; como Acuerdo Internacional, fue el instrumento jurídico internacional encargado de regular los intercambios comerciales internacionales y de establecer las obligaciones y derechos para los países que lo suscribieron. Como Institución fue el organismo internacional más completo que sirvió como foro para que las Partes contratantes administraran sus relaciones comerciales y llevaran a cabo negociaciones destinadas a eliminar los obstáculos al comercio internacional (Álvarez Soberanis, 1979, pág. 110).

\section{Los principios rectores del GATT}

Los principios rectores del GATT, fueron, y siguen siendo, la piedra angular del Acuerdo. Los principios que inspiran la estructura normativa del Acuerdo son:

1. el principio de no discriminación;

El principio de no discriminación, ha sido un principio fundamental del GATT. Este principio se refiriere la igualdad de todos los países que forman parte del GATT. "El principio de la no discriminación en materia de comercio internacional, se traduce en el tratamiento igualitario otorgado a la inesperada, o tránsito de productos en un territorio aduanero determinado, cualquiera que sea su origen o destino". El principio de no discriminación 
en los tratados comerciales, tiene una doble finalidad:

a. impedir que las partes contratantes se discriminen entre sí, e;

b. impedir tratamientos que favorezcan a terceros en detrimento de las partes contratantes.

2. el del tratamiento nacional;

El principio del tratamiento nacional. Este principio persigue también la igualdad internacional de productos extranjeros. En la práctica de lesiona al proceso de desarrollo del que han decidido seguir las naciones del llamado tercer mundo. Este principio consiste en equiparar a nacionales de extranjeros, sobre todo lo que se refiere a los efectos de la tributación interna sobre el comercio internacional.

3. el de reciprocidad.

El principio de reciprocidad. Los Estados parte en el acuerdo deben otorgar a cualquier otro Estado parte, el tratamiento de la nación más favorecida, lo que quiere decir que, cualquier concesión tarifaría u otra acordada por uno de esos Estados a un producto originario de otro Estado o destinado a él (no necesariamente parte en el acuerdo) debe ser extendida de manera inmediata e incondicional al mismo producto importado o exportado de los demás Estados partes.

Existen, sin embargo excepciones importantes al principio de nación más favorecida, a saber: ventajas al tráfico fronterizo; tratamiento preferencial en zona preexistente (Common Wealth, Unión Francesa, Benelux); ventajas propias de las uniones aduaneras o zonas de libre comercio, en las condiciones del artículo XXIV del acuerdo; y tarifas preferenciales concedidos por los Estados industrializados a las importaciones de los Estados en vías de desarrollo, incluyendo las ventajas especiales a los menos desarrollados, bajo el llamado sistema de preferencias generalizadas, y las tarifas y otras concesiones comerciales vigentes exclusivamente entre los Estados en desarrollo sobre una base global o regional.

\section{El principio de nación más favorecida}

El efecto que produce la cláusula de la nación más favorecida, es que todas las partes del Acuerdo se hacen acreedoras a las concesiones negociadas en el seno del Acuerdo. Las principales prerrogativas de negociar dentro del GATT son que permite a los Estados miembros primero:

1. la posibilidad de que sus productos tengan acceso al mercado internacional y,

2. le otorga la confianza de que sus productos podrán tener acceso a otros Estados sin tener que enfrentarse a excesivas trabas arancelarias o no arancelarias.

No obstante, estas ventajas dependen de las perspectivas económicas y comerciales que se tengan en ventaja o desventaja con los demás miembros del Acuerdo, y de esto dependerá la realidad del beneficio que se

${ }^{10}$ Publicado en el Diario Oficial de la Federación (DOF) el 28 de abril de 1988. 
pueda obtener (García Amor, 1980, págs. 189-190).

\section{Las Rondas de Negociaciones}

La principal actividad de los miembros del GATT, fue el llevar a cabo negociaciones multilaterales las cuales son mejor conocidas como rondas. En ellas, las partes dieron observancia a los Objetivos del Acuerdo. Hubo 8 rondas y fue precisamente en el seno de estas, donde se dieron los avances más importantes para la liberalización del comercio internacional. El patrón de referencia para las negociaciones sería el propio GATT (Lobejón Herrero, 2001, pág. 33).

1ª Ronda Ginebra (1947). La Ronda adoptó el nombre del lugar donde se celebró y se trataron temas referentes a los aranceles (al igual que las subsiguientes tres), en ella antevinieron 23 países; 2a Ronda Annecy (1949), en ella participaron 13 países. $3^{a}$ Ronda Torcuay (1951), en la que participaron 38 países; Ronda Ginebra (1956), participaron 26 países; Ronda Dillon (1960-1961), la cual se celebró en Ginebra (al igual que las consecutivas rondas), en la que se abarcaron temas de aranceles, participando en ella 26 países; Ronda Kennedy (1964-1967), se trataron temas de aranceles y medidas antidumping, con una participación de 62 países; Ronda Tokio (1973-1979), aranceles, medidas no arancelarias, y acuerdos relativos al marco jurídico, con una participación de 102 participantes y; Ronda Kennedy (1986-1994), en esta se trataron temas referentes a árenseles, medidas no arancelarias, normas, servicios, propiedad intelectual, solución de diferencias textiles, agricultura, la creación de la OMC, etc., con una participación de 123 países.

El GATT ha sido enmendado en diversas ocasiones y acompañado de acuerdos complementarios, en la actualidad son parte del Acuerdo 91 Estados, con sede en Ginebra de su Dirección General (Pastor Ridruejo, 2001, pág. 78). El Acuerdo General contiene disposiciones sobre solución de controversias, en donde cabe señalar que en caso de controversia los Estados parte de la misma, tienen la obligación de consultarse para llegar a un arreglo amistoso. Si se diese la situación en que este arreglo no se consiguiese, la parte agraviada puede recurrir a la Conferencia de los Estados parte para que le autorice suspender la ejecución de la parte equivalente de sus obligaciones hacia el Estado culpable, procedimiento del que sólo se ha hecho uso en una única ocasión. Pero, con independencia de estas disposiciones de carácter convencional, se ha elaborado gradualmente en la práctica del GATT un conjunto de mecanismos de conciliación y mediación, como la creación de partes de trabajo o paneles, establecidos por la Conferencia.

Es importante señalar que en virtud del Acuerdo firmado en Marrakech el día 15 de abril de 1994 se crea la Organización Mundial del Comercio (OMC), que propiamente hablando no comporta la desaparición de los compromisos convencionales asumidos en el marco del GATT.

Estos compromisos forman parte ahora de los acuerdos comerciales multilaterales por cuya aplicación 
debe velar la OMC, cuyo ámbito de aplicación sigue siendo el comercio de mercancías, como lo fue el GATT. La $\mathrm{OMC}$, igualmente ha establecido una serie de compromisos relativos al comercio de servicios, tal y como lo es el Acuerdo sobre comercio de servicios, el Acuerdo sobre los aspectos de los derechos de propiedad intelectual relacionados con el comercio y el Acuerdo relativo a las inversiones vinculadas al comercio. En cualquier caso, el acuerdo de Marrakech configura, desde el principio y sin duda alguna, a la OMC como una auténtica organización internacional, con una estructura orgánica sumamente compleja. Entre los órganos de que dispone merece mención especial el encargado de la solución de controversias, que, junto a cometidos de conciliación institucionalizada, lleva a cabo también funciones auténticamente jurisdiccionales (Pastor Ridruejo, 2001, pág. 78).

\section{La Solución de Controversias en el GATT}

Dentro del sistema del GATT de 1947, tuvo lugar el sistema de solución de controversias y sirvió tanto como mecanismo como instrumento jurídico para su desarrollo y aplicación. El GATT como mecanismo de solución de controversias por varias décadas, llego a adquirir tal relevancia que su proceso llego a ser de los más utilizados en el escenario internacional (Montaña Mora, 1997, págs. 47-51).Con el tiempo el sistema del GATT sobre este tema, se fue deteriorando y dejó de ser efectivo para el arreglo de conflictos (Cruz Miramontes, 2003, pág. 59).

Las controversias en el GATT se disipaban mediante la instauración de grupos especiales a los que se les conocía comúnmente como paneles, los cuales estudiaban los hechos y las disposiciones del GATT aplicables y formulaban un informe cuya eficacia jurídica dependía de que fuera aprobado por el órgano plenario del GATT. El procedimiento fue codificado en el entendimiento sobre solución de diferencias aprobada la ronda de Tokio (1973-1979).

El sistema de solución de diferencias comerciales internacionales se encuentra bajo el contexto institucional de la Organización Mundial de Comercio. El proceso de solución de controversias del GATT se desarrolló bajo un conjunto de procedimientos tradicionales. El nuevo proceso de solución de controversias de la OMC se basa en buena parte en el proceso tradicional de GATT por lo tanto los procesos de solución de controversias de la $\mathrm{OMC}$ se desarrollan bajo un conjunto de procedimientos tradicionales.

El principal antecedente histórico de la OMC como mecanismo e instrumento de solución de controversias en definitiva es el GATT de 1947, en concreto los artículos XXII y XXIII del GATT de 1947, los cuales constituyen el eje central del procedimiento y son idénticos a los del GATT de 1994 con algunas salvedades (Montaña Mora, 1997, pág. 52). La mayoría de los Tratados comerciales al seguir el sistema del GATT, también combinan reglas de conducta en política comercial con detallados procedimientos multilaterales 
de solución de controversias.

\section{LA OMC}

\section{Introducción}

Es la organización internacional Multilateral o intergubernamental que vigila la regulación del comercio internacional y se propone reducir los obstáculos al mismo, denominada Organización Mundial del Comercio (OMC) y en inglés The World Trade Organization “WTO”.

La OMC se incorpora y completa finalmente el sistema de Bretton Woods, y ahora junto con el FMI y al BM, cumplen con los principales objetivos del sistema de impulsar el desarrollo y estabilidad de la economía mundial, el intercambio comercial internacional y la estabilidad del contexto financiero. Hoy por hoy la OMC es el elemento esencial para el comercio y la economía mundial, gracias a ella se ha dado un impulso político a las transacciones comerciales, así como al sector de la regulación del comercio internacional, por ellos se le considera la piedra angular del sistema multilateral del comercio, destinada a gestionar su liberalización.

La OMC es la primera organización internacional que abandera el sistema jurídico e institucional formal del comercio internacional. Es el resultado de los intereses de los Estados que dirigen la agenda del comercio internacional. La OMC ha producido considerables repercusiones en la sociedad internacional, ya que tiene implicaciones económicas, sociales como medioambientales. La organización de la OMC descansa sobre una estructura institucional y jurídica. La OMC no es más que la moldura jurídica del comercio internacional. La OMC es la expresión económica y política.

\section{Antecedentes}

Los antecedentes históricos de la OMC, son los propios del GATT y el mismo proceso histórico de casi 46 años en el que se desarrolló el sistema de éste, aunque su antecedente más inmediato es la Ronda de Tokio (Patiño Manfer, 1994, pág. 735).

En las preliminares Rondas de negociaciones a la de Tokio, la prioridad de sus miembros fue la reducción y eliminación de los aranceles; medida proteccionista que hasta este momento se había considerado como principal obstáculo al comercio internacional y sobre la que se puso especial énfasis por parte de los miembros del GATT.

En la Ronda de Tokio las negociaciones tomaron un nuevo rumbo al analizar la condición que guardaba en ese momento el comercio internacional y la nueva dirección que estaba tomando las medidas proteccionistas por parte de los Estados. 
Para la década de los años 70 el comercio internacional necesitaba indudablemente un nuevo giro para continuar con su liberalización y no bastaba ya con la eliminación o disminución de los aranceles, era necesario una nueva regulación comercial. Así en la Ronda no solo se negoció el tema de los aranceles sino también temas referentes a medidas no arancelarias y acuerdos relativos al marco jurídico. Por tal motivo se le considero en su momento como la más ambiciosa, hasta que se celebró la de Uruguay (Patiño Manfer, 1994, pág. 735).

De las negociaciones sobre temas no arancelarios surgieron una serie de acuerdos mejor conocidos como "códigos", que en algunos casos interpretaban normas del GATT y otros abrían nuevas vías. Estos Acuerdos fueron; Acuerdo Sobre Comercio de Aeronaves Civiles; Acuerdo Relativo a la Aplicación del artículo VI del acuerdo General Sobre Aranceles aduaneros y comercio y Acuerdo Relativo a la Interpretación y Aplicación de los Acuerdos VI, XVI y XXIII del Acuerdo General Sobre Aranceles Aduaneros y Comercio (Acuerdos Antidumping); Declaración sobre las medidas comerciales Adoptadas por Motivos de Balanza de Pagos; Acuerdo Sobre Compras del Sector Público; Acuerdo Sobre Procedimientos para tramite de Licencias de importación; Acuerdo sobre Obstáculos Técnicos al Comercio y Trato Diferenciado y más favorable, reciprocidad y mayor participación de los países en Desarrollo (Países en desarrollo); Medidas de Salvaguardia adoptadas por motivos de desarrollo; Entendimiento Relativo a las notificaciones; las consultas, la solución de diferencias y la vigilancia; Acuerdo Relativo a la Interpretación y Aplicación de los Artículos VI; XVI Y XXIII del Acuerdo General Sobre Aranceles Aduaneros y Comercio; Trato Diferenciado y más favorable, Reciprocidad y Mayor Participación de los Países en Desarrollo; Acuerdo Relativo a la Aplicación del Artículo VII del Acuerdo General sobre Aranceles Aduaneros y Comercio; Acuerdo de la Carne de Bovino; Acuerdo Internacional de los Productos Lácteos.

Estos códigos sólo eran aplicables para aquellos países que los aceptaban (Lal Das, 2004, pág. 19 y 21) y varios de estos acuerdos fueron modificados en la Ronda de Uruguay y se convirtieron en compromisos multilaterales aceptados por todos los miembros de la OMC. Después de casi 46 años, más de 106 países, por fin, se pusieron de acuerdo y decidieron aceptar y ratificar el Acuerdo para la creación de una organización internacional para administrar el sistema multilateral de comercio.

\section{El Origen de la OMC}

La crisis del sistema multilateral de comercio encabezado por el GATT, la poca importancia que comenzó a tener la corriente liberalizadora, el incremento de las tentaciones neoproteccionistas de los principales actores del comercio internacional y el deficiente funcionamiento de algunos de los acuerdos aprobados en la ronda de Tokio puso de manifiesto la necesidad de reforzar el sistema del GATT. 


\section{La Ronda Uruguay}

El origen de la OMC, tuvo lugar en el seno de las negociaciones de la Ronda Uruguay, pero antes de abordar el tema, hay que destacar a la Reunión Ministerial celebrada en Ginebra por los miembros del GATT en noviembre de 1982, como primer antecedente de la Ronda. Esta Reunión tenía por cometido dar inicio a una nueva Ronda de negociaciones (Montaña Mora, 1997, pág. 3), pero los resultados fueron un fracaso. El programa de trabajo discurrió sobre cuestiones de servicios, inversiones y alta tecnología, y en especial en el área de agricultura. Este trabajo sirvió más tarde de base para el programa de las negociaciones, incluido en la Declaración Ministerial, que dio inicio a la Ronda Uruguay (Lal Das, 2004, pág. 23). En 1985 se reúne el Comité y en enero de 1986 comenzó a instar la propuesta de temas para incluirlos en la agenda y posteriormente en la Declaración Ministerial que aprobaría la Ronda (Montaña Mora, 1997, pág. 3).

El 15 de septiembre 1986, en sesión extraordinaria, dio inicio la Reunión Ministerial de las Partes Contratantes del GATT, en Punta del Este Uruguay y el 20 del mismo mes, adoptaron la llamada "Declaración de Punta del Este" en la que se declaró dar inicio a la nueva Ronda de negociaciones comerciales multilaterales (la Ronda Uruguay). En esta misma reunión, se constituyó un Comité para que dirigiera y encaminara las negociaciones (Comité de Negociaciones Comerciales). Estaba previsto que las negociaciones deberían concluirse en un plazo de cuatro años, es decir en 1990 pero finalmente se extendieron a siete años concluyendo finalmente en 1993. Las causas de la dilatación de la conclusión de la Ronda fueron principalmente por la profundidad de los objetivos establecidos para las negociaciones de la Ronda que aunaban en diversos temas y en que los países desarrollados y en desarrollo no lograban llegar a arreglos pues obviamente cada sector protegía sus intereses y así los querían plasmar en los acuerdos que se estaban negociando, lo que originaba constantes discrepancias. La Ronda finalizó el 15 de abril de 1994 en Marrakech (Patiño Manfer, 1994, pág. 738).

En la Declaración de Punta del Este se establecieron los objetivos y las reglas que rigieron las negociaciones de la Ronda y el programa de trabajo que indicaba los temas que se tratarían en las negociaciones. Los Fines de la Reunión ministerial fueron en un principio los de: reducir el proteccionismo y eliminar las distorsiones del comercio; preservar los principios y promover sus objetivos del GATT.

Entre sus objetivos, estuvieron los de poner especial énfasis en la liberalización y expansión del comercio de los países en desarrollo; la reducción y eliminación de los aranceles, las restricciones cuantitativas y otras medidas y obstáculos no arancelarios que distorsionaren y restringieren el comercio así como contraviniesen las disposiciones del GATT; revisar y reforzar el funcionamiento y estructura del sistema del GATT y, ampliar la cobertura incluyendo nuevas áreas como los servicios, la propiedad intelectual, las inversiones (Montaña Mora, 1997, págs. 5-7). 


\section{Evolución de la Ronda Uruguay}

En la Ronda Uruguay, la idea de incluir un acuerdo estableciendo una organización internacional de comercio fue formulada poco después de empezar la ronda por Renato Ruggiero, entonces ministro de comercio italiano, quien tras finalizar la ronda Uruguay acabaría siendo nombrado director general de la organización (Montaña Mora, 1997, pág. 12).

Se establecieron grupos de negociación y sus objetivos, el 28 de enero de 1987 se diseñaron y convinieron los planes de negociación para cada uno de los 14 temas relacionados con el comercio de mercancías, con lo cual fue posible iniciar las negociaciones específicas. Con excepción del grupo sobre salvaguardias, los 13 grupos restantes acordaron llevar a cabo las negociaciones en dos fases la primera sirvió para identificar los principales asuntos a negociar, así como para exponer las propuestas por parte de las delegaciones la segunda fase le sirvió para establecer los puntos específicos a negociar. Después de más de siete años de haber iniciado las negociaciones multilaterales, el 15 de diciembre de 1993 se concluyó el acta final en la que se contienen los resultados a que llegaron las partes contratantes. Los resultados finales se recogen en un documento clasificado bajo las siglas MTN/FA.

Uno de los resultados de la Ronda Uruguay fue el desdoblamiento de lo que era el original GATT en dos acuerdos nuevos "El Acuerdo General sobre Aranceles y Comercio de 1994" " "el Acuerdo por el que se establece la Organización Mundial del Comercio"(Montaña Mora, 1997, pág. 7).

El acta final de la Ronda Uruguay, es el resultado de las negociaciones celebradas en el centro de la antigua institución del GATT entre 1986 y 1994. En ella se incorporaron los Acuerdos multilaterales que fueron negociados en la misma Ronda y que hoy conforman la gran mayoría de los llamados Acuerdos de la OMC o los Textos Jurídicos de la OMC. Por lo tanto, la mayoría de los acuerdos de la OMC son el resultado de las negociaciones comerciales de la Ronda Uruguay.

Gran parte de las negociaciones de la Ronda Uruguay discurrieron en revisiones del propio GATT de 1947 y sus acuerdos multilaterales y plurilaterales que lo constituían. Algunos, como el acuerdo general sobre comercio de servicios, fue un acuerdo nuevo.

El acuerdo por el que establece la organización Mundial del Comercio y fue firmada por 125 países. El Acuerdo está constituido por dieciséis artículos, y vital relevancia tienen los artículos primero y octavo del acuerdo ya en el primero se reconoce el establecimiento de la OMC y el octavo su personalidad jurídica (Witker \& Hernández, Régimen Jurídico del comercio exterior en México, 2002, pág. 67).

El Acuerdo de la Ronda Uruguay firmado en Marrakech en abril de 1994 para establecer la OMC. Desde luego, consideramos que el logro más relevante de la ronda Uruguay es, sin duda, la creación de la organización mundial del comercio, como un organismo especializado de las Naciones Unidas y a la que se le encomienda, 
según disposición del artículo 3 del acuerdo por el que se establece su creación, bajo el rubro "funciones de la $O M C^{\prime \prime}$, las siguientes, la aplicación administración y funcionamiento del propio acuerdo constitutivo, al que se incorporan pasando a formar parte del mismo, los acuerdos y los instrumentos jurídicos incluidos en los anexos 1 2.03 que son vinculantes para todos los miembros de la hoy en ese, así como los acuerdos e instrumentos jurídicos incluidos en el anexo 4, conocidos como acuerdos comerciales plurilaterales que también forman parte de la OMC y tienen carácter vinculante para los miembros que lo hayan suscrito. A continuación, mencionamos por su nombre oficial. La OMC, recogen acuerdos obligatorios para los países miembros, denominados acuerdos multilaterales.

\section{Objetivos de la OMC}

Los objetivos básicos de la OMC se establecen en el preámbulo de su Acuerdo Constitutivo. Tales objetivos tienen una característica peculiar, su similitud a los del GATT ${ }^{11}$.

En si los objetivos del GATT fueron tomados como base para los de la OMC, con la excepción que los de ésta fueron ampliados y que se introdujeron nuevos designios en consideración al contemporáneo comercio internacional, como: acrecentar el comercio de servicios, preservar y proteger el medio ambiente y promover el desarrollo económico (Patiño Manfer, 1994, pág. 742). No obstante, los objetivos continúan siendo poco perfilados y definidos y hasta cierto punto resultan confusos.

El primer propósito de la OMC es promover y acrecentar entre sus miembros relaciones en la esfera de la actividad comercial y económica (comercio de bienes y servicios y producción). A través de estas relaciones comerciales y económicas:

1. Crear, elevar y mantener en constante crecimiento, empleos que contribuyan a elevar los niveles de vida y los ingresos reales de los trabajadores de sus países miembros.

2. Permitir una mejor utilización y expansión de los recursos económicos y naturales sustentados en el desarrollo sostenible.

3. Procurar, proteger y preservar el medio ambiente

4. Realizar esfuerzos para que los países en desarrollo, y especial los menos adelantados, obtengan una parte del incremento del comercio internacional que corresponda a las necesidades de su desarrollo económico.

\footnotetext{
${ }^{11}$ Los Objetivos del GATT a su vez eran los objetivos de la OIC solo que un poco más sencillo, que las de esta última.
} vol.10, no. 04, Rio de Janeiro, 2017.pp. 2637-2655 


\section{Funciones de la OMC}

Como principal función de la $\mathrm{OMC}$, se ha de mencionar que es la de trabajar en la observancia y logro de sus objetivos. Asimismo, Facilitar la aplicación, administración y funcionamiento de su Acuerdo Constitutivo, de los Acuerdos Comerciales Multilaterales y Bilaterales.

Igualmente, ha de servir de foro para las negociaciones comerciales multilaterales y bilaterales que hayan negociado sus miembros en la Ronda Uruguay y que han quedado establecidos en su acuerdo constitutivo de la OMC y de futuros acuerdos negociaciones en el marco de la OMC. También servirá de marco para la aplicación de los resultados de las relaciones comerciales, según decida la conferencia ministerial.

Ha de dirigir el "Entendimiento relativo a las normas y procedimientos por lo por los que se rice la solución de diferencias" y el "Mecanismo de examen de las políticas comerciales"

También se cuenta como función de la OMC, la de cooperar con el Banco Mundial y el Fondo Monetario Internacional y sus organismos conexos en la formulación de políticas económicas a escala mundial

\section{Estructura jurídica de la OMC}

Los pilares sobre los que descansa la OMC son los llamados Acuerdos de la OMC o Instrumentos jurídicos de la OMC. Los acuerdos de la OMC son el resultado de las negociaciones los propios gobiernos miembros.

Los acuerdos de la OMC han sido negociados y firmados y ratificados por la mayoría de los países partir que participar en el comercio mundial. Los acuerdos de la OMC deben de ser firmados y ratificados por los Estados que lo deseen hacer. La OMC como instrumento jurídico es el conjunto de normas que regula la manera en que los gobiernos deben elaborar y aplicar sus leyes y reglamentos relacionados con el comercio. Los Acuerdos de la OMC son los instrumentos jurídicos que dan subsistencia al Derecho de la OMC. Los acuerdos de la OMC son el apoyo jurídico del sistema internacional del comercio.

\section{CONCLUSIONES}

Si bien puede parecer extraño un artículo de esta naturaleza, para el autor guarda especial interés recordar la razón de un libre comercio como una necesidad para el mantenimiento de una paz de orden mundial, puesto que habiendo visto lo que sucede en Estados Unidos y los nuevos aires que soplan desde el Brexit y los nuevos nacionalismos europeos encumbrándose y encontrando espacios en la democracia que no han sabido ser bloqueados por nuevas opciones, pareciera que nos dirigimos a un nuevo proteccionismo comercial, que como ya se mencionó, puede dar pauta a conflictos de otro tipo en el mediano plazo. 
El comercio internacional no es nada más una forma de compra - venta, es una forma de acercamiento entre las personas e intercambios culturales que animan a las personas a verse como iguales y no como rivales, es, por tanto, necesario recordar cual fue el origen de este tipo de organizaciones (la segunda guerra mundial) y como se previó eliminarlas como riesgo. Igualmente es altamente clarificador de los fines y objetivos planteados en las conferencias lo dicho por Henry Morgenthau en su discurso de apertura en la conferencia de Bretton Woods, el... "desconcierto y la amargura" que resultaron de la depresión se convirtieron en "caldo de cultivo para el fascismo y finalmente, la guerra" así, las instituciones ahí creadas facilitarían "la creación de una comunidad mundial dinámica en la cual las gentes del mundo puedan alcanzar su potencial en paz" (Bretton Woods Project, 2008) recordarlas y rememorarlas se hace entonces una necesidad.

\section{HISTORICAL-LEGAL ANTECEDENTS OF CONTEMPORARY INTERNATIONAL}

\section{TRADE}

\section{Abstract}

The multilateral trading system is a system that has formed a common ideal of a fair and open world trade. A system that has directly contributed to the removal of trade barriers between states and a system whose structure is based on rules of a legal nature and the principle of non-discrimination. The current multilateral trade system has been shaped over the last 50 years of the twentieth century, a period in which they are created and outlined the existence of multilateral economic institutions. This system relies on an international framework of rules and obligations that regulate trade between states, the evolutionary analysis be done on this is therefore essential to understand the future of international trade.

Keywords: international trade, historical background, international trade law, private international law.

\section{BIBLIOGRAFÍA}

ÁLVAREZ SOBERANIS, J. (1979). El GATT: antecedentes y prósitos. Jurídica. Anuario del Departamento de Derecho de la Universidad Iberoamericana (11).

BRETTON WOODS PROJECT. (22 de febrero de 2008). Qué son las instituciones Bretton Woods? Recuperado el 5 de noviembre de 2016, de brettonwoodsproject.org: http://www.brettonwoodsproject.org/es/2008/02/art-560735/

CRUZ MIRAMONTES, R. (2003). Las relaciones comerciales multilaterales de México y el Tratado de Libre Comercio con la Unión Europea. México: IIJ/UNAM. 
DE LA PENA, R. M. (1980). Las preferencias del Comercio Internacional (El sistema generalizado de preferencias para las exportaciones mexicanas). México, México: Instituto de Investigaciones Jurídicas de la UNAM.

DÍAZ MIER, M. Á. (1996). Del GATT a la OMC. Madrid: Sintesis.

GARCÍA AMOR, C. (1980). El GATT, el porqué de la negatividad de la incorporación de México, estructura y opiniones. Jurídica. Anuario del Departamento de Derecho de la Universidad Iberoamericana (12).

LAL DAS, B. (2004). La OMC y el sistema multilateral de comercio: pasado, presente y futuro. Madrid: Icaria Editorial.

LOBEJÓN HERRERO, L. F. (2001). El Comercio Internacional. Madrid: Akal.

MILLET, M. (2001). La Regulación del Comercio Internacional: del GATT a la OMC (Vol. 24). Barcelona, España: La Caixa.

MONTAÑA MORA, M. Á. (1997). La OMC y el reforzamiento del sistema GATT: una nueva era en la solución de diferencias comerciales. Madrid: McGraw-Hill.

NEGRO, S. C. (2004). De Marrakech a Cancún: La Organización Mundial de Comercio y las Conferencias Ministeriales. Temas de Derecho Industrial y de la Competencia. Derecho de la Competencia.

PASTOR RIDRUEJO, J. A. (2001). CURSO DE DERECHO INTERNACIONAL PUBLICO Y ORGANIZACIONES INTERNACIONALES (Octava ed.). Madrid: Tecnos.

PATIÑO MANFER, R. (1994). Creación de la Organización Multilateral de Comercio (OMC). Boletín Mexicano de Derecho Comparado (81).

TAMAMES, R., \& Huerta, B. (2003). Estructura Económica Internacional (Vigésima ed.). Madrid: Alianza.

VARELA PARACHE, M. (1969). El Fondo Monetario Internacional. Madrid: Biblioteca Universitaria de Economía (Guadiana).

WITKER, J. (1979). Principios y estructura del GATT. Boletín Mexicano de Derecho Comparado (36).

WITKER, J., \& HERNÁNDEZ, L. (2002). Régimen Jurídico del comercio exterior en México (Segunda ed.). México: Instituto de Investigaciones Jurídicas UNAM.

Trabalho enviado em 19 de janeiro de 2017.

Aceito em 02 de setembro de 2017. 